\title{
Erratum to: Secretin-stimulated MRCP
}

N. J. Lee, ${ }^{1,2}$ K. W. Kim, ${ }^{1}$ T. K. Kim, ${ }^{1,3}$ M. H. Kim, ${ }^{4}$ S. Y. Kim, ${ }^{1}$ M.-S. Park, ${ }^{1,5}$ A. Y. Kim, ${ }^{1}$ H. K. Ha, ${ }^{1}$ P. N. Kim, ${ }^{1}$ M.-G. Lee ${ }^{1}$

${ }^{1}$ Department of Radiology, Asan Medical Center, University of Ulsan College of Medicine, 388-1, Pungnap 2-dong, Songpa-gu, Seoul 138-736, Korea

${ }^{2}$ Department of Radiology, Eulgi Medical Center, 280-1, Hagye-dong, Nowon-gu, Seoul 139-711, Korea

${ }^{3}$ Department of Medical Imaging, Toronto General Hospital, 200 Elizabeth St, Toronto, Ontario, Canada M5G2C4

${ }^{4}$ Department of Internal Medicine, Asan Medical Center, University of Ulsan College of Medicine, 388-1, Pungnap 2-dong, Songpa-gu, Seoul 138-736, Korea

${ }^{5}$ Department of Radiology, Yong Dong Severance Hospital, 146-92 Dokok-dong, Kangnam-ku, Seoul 137-270, Korea

\section{Erratum to: Abdom Imaging (2006) 31:575-581 DOI 10.1007/s00261-005-0118-X}

This article was inadvertently published a second time under DOI: 10.1007/s00261-006-9108-x.

Official publication is under DOI: 10.1007/s00261-005-0118-x appearing in Abdom Imaging (2006) 31:575-581.

The online version of the original article can be found under doi:10.1007/s00261-005-0118-x.

Correspondence to: K. W. Kim; email: kimkw@amc.seoul.kr 